Article

\title{
Uncertainty in Irrigation Return Flow Estimation: Comparing Conceptual and Physically-Based Parameterization Approaches
}

\author{
Jung-Hun Song $\left.{ }^{1}{ }^{(}\right)$, Younggu Her ${ }^{1}\left(\mathbb{D}\right.$, Soonho Hwang ${ }^{2}{ }^{(0)}$ and Moon-Seong Kang ${ }^{3, *}$ \\ 1 Department of Agricultural and Biological Engineering \& Tropical Research and Education Center, \\ University of Florida, Homestead, FL 33031, USA; junghunsong@ufl.edu (J.-H.S.); yher@ufl.edu (Y.H.) \\ 2 Research Institute of Agriculture and Life Sciences, Seoul National University, Seoul 08826, Korea; \\ ynsgh@snu.ac.kr \\ 3 Department of Rural Systems Engineering, Research Institute of Agriculture and Life Sciences, Institutes of \\ Green Bio Science and Technology, Seoul National University, Seoul 08826, Korea \\ * Correspondence: mskang@snu.ac.kr; Tel.: +82-2-880-4582; Fax: +82-2-873-2087
}

Received: 19 March 2020; Accepted: 13 April 2020; Published: 15 April 2020

\begin{abstract}
Irrigation return flow (RF) is a critical component of the water cycle in an agricultural watershed, influencing the flow regime of downstream river. As such, it should be accurately quantified when developing water resources management plans and practices. Although many studies have proposed ways to quantify RF, uncertainty in RF estimates has not been determined to improve reliability and credibility. This study examines how conceptual (CON) and physically-based (PHY) parameterization approaches affect RF uncertainty. Results showed that PHY had a smaller amount of RF uncertainty compared to CON, as parameters of the PHY approach could be regulated based on their physical meanings. This study also found that the application of constraints created based on the relationship between the conceptual parameter and physical characteristics of irrigated plots could effectively reduce RF uncertainty made using the CON approach. This study demonstrates the benefits of the physically-based parameterization approach and the application of constraints on conceptual parameters to RF estimation.
\end{abstract}

Keywords: irrigation return flow; uncertainty; drainage routing schemes; ungauged watersheds; physically-based parameter; conceptual parameter

\section{Introduction}

Irrigation water supplied from sources such as reservoirs, pumping stations, and tube wells may not be consumed in plots and rather may directly discharge into drainage canals and downstream streams. Such water is known as irrigation return flow $(\mathrm{RF})$, affecting the flow regime of the downstream rivers [1-6]. RF is an important part of the water balance of a watershed and a critical factor requiring consideration when developing water resources management plans and practices, determining the operation rule of irrigation systems, and assessing environmental water use [7-9]. The quantification of RF is often complicated with human activities such as irrigation and farm management as well as the variations of rainfall and temperature. This is particularly the case for ungauged watersheds $[8,10,11]$.

RF can be quantified using monitoring and modeling approaches. Previous studies have estimated RF by measuring the amount of water irrigated, infiltrated, and drained during the nonrainy season, assuming that RF should be negligible during rainy days [12-14]. However, other studies have reported that a large amount of RF may discharge into rivers during rainy days from watersheds in which irrigation water is heavily used $[6,8,15]$. Such a finding suggests that for accurate RF estimation, routing processes of irrigation water in an extensively irrigated watershed should not be ignored on 
rainy days. A modeling approach has been recommended to effectively differentiate runoff by rainfall and RF by irrigation in runoff drained from a plot $[3,16,17]$.

RF can be estimated by simulating the overall water balance, which consists of rainfall, irrigation, surface drainage, evapotranspiration, and infiltration. Surface drainage is a key variable for quantifying $\mathrm{RF}$, and two parameterization schemes are commonly used to describe surface water drainage processes: conceptual and physically-based approaches. The conceptual approach (CON) employs parameters that are conceptually defined (rather than physically) using the linear reservoir theory [11,18-21]. On the other hand, a physically-based parameterization approach (PHY) represents the drainage processes using the broad-crested weir equation [3,7,22-25].

Parameterization schemes have their own strengths and weaknesses in terms of complexity, accuracy, and uncertainty. Even when there are no drainage observations for calibration, for instance, the parameter values of PHY may be accurately estimated from their physical meanings. In contrast, it can be difficult to reasonably determine the values of conceptual parameters without calibration due to the scale-dependency of system heterogeneity and nonlinearity [26]. In the case of an ungauged watershed, the applicability of conceptual parameters has not received sufficient systematic analysis to guide the selection of approaches.

This study evaluated the applicability of conceptual and physically-based parameterization approaches for estimating RF of ungauged watersheds. The accuracy and uncertainty of RF estimates made using the two approaches were compared to each other. We also discuss how expert knowledge can help refine the value range of a conceptual parameter, aiding the reduction of uncertainty in the conceptual approach $[27,28]$. This study demonstrates how hydrological reasoning can be instrumental in reducing the uncertainty for ungauged watersheds.

\section{Estimation of Irrigation Return Flow}

\subsection{Mathematical Representation of Irrigation Return Flow}

$R F$ is defined as the amount of irrigation water that is directly drained or infiltrated rather than consumed by plants in a plot, eventually returning to downstream water bodies and/or aquifers $[1,3,16,17] . R F$ can be divided into two components:

$$
R F_{t}=Q R F_{t}+D R F_{t}
$$

where $Q R F$ is quick return flow $(\mathrm{mm})$ drained from the ground surface including irrigation and drainage ditches; $D R F$ is delayed (irrigation water) return flow $(\mathrm{mm})$ infiltrated in paddy fields and later discharged to the stream [16,17]; and $t$ is the time step (day). QRF can be divided further into two parts based on the places from which they are drained:

$$
Q R F_{t}=D M W R_{t}+P R F_{t}
$$

where $D M W R$ is delivery management water requirement (mm); and $P R F$ is quick (irrigation water) return flow drained through individual paddy field outlets and discharged to drainage ditches $(\mathrm{mm})$. $D M W R$ is the agricultural water used to maintain a desired water level in irrigation ditches and directly discharged from the irrigation ditches to downstream drainage canals or streams (Figure 1). The RF ratio is defined as the ratio of the amount of RF to the agricultural water supplied:

$$
R_{R F}=R_{Q R F}+R_{D R F}=\frac{Q R F}{A W S}+\frac{D R F}{A W S}
$$

where $A W S$ is agricultural supply (mm); $R_{R F}$ is total RF ratio; and $R_{Q R F}$ and $R_{D R F}$ are the ratios of $Q R F$ and $D R F$ to $A W S$, respectively. 
(a) Irrigation and drainage block

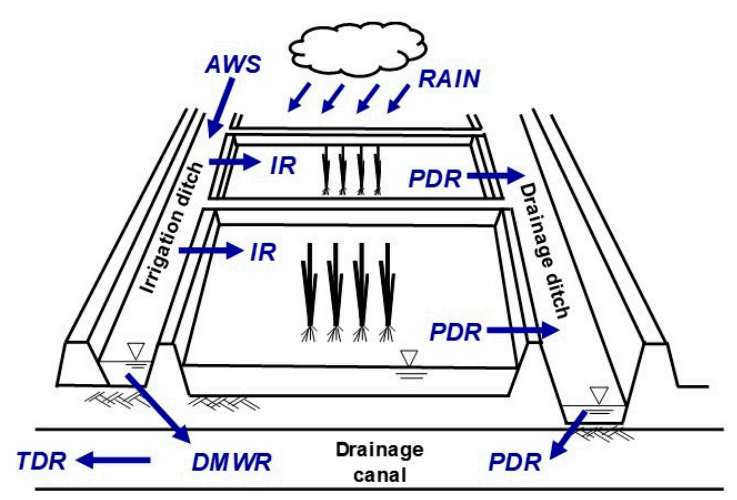

(b) Paddy field

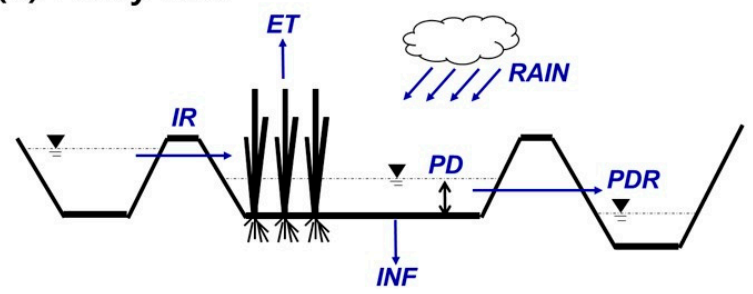

\begin{tabular}{|c|l|}
\hline$R A I N$ & Rainfall \\
$A W S$ & Agricultural water supply \\
$I R$ & Irrigation water \\
$D M W R$ & Delivery management water \\
$P D R$ & requirement \\
$T D R$ & Paddy field drainage \\
$P D$ & Total surface drainage \\
$E T$ & Ponding depth \\
$I N F$ & Actual evapotranspiration \\
$L H$ & Height of the paddy field outlet \\
$W$ & Weir width perpendicular to the \\
\hline
\end{tabular}

(c) Field outlet

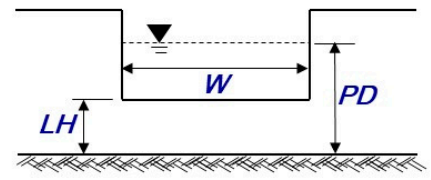

Figure 1. Schematic of the water balance in paddy fields; (a) irrigation and drainage block, (b) paddy field, and (c) field outlet [29].

\subsection{Paddy Drainage Model}

$R F$ is a part of drainage in a cultivated area. At the paddy block scale, the components of surface water draining out of the main outlet can be expressed as:

$$
T D R_{t}=D M W R_{t}+P D R_{t}
$$

where TDR is total surface drainage in a paddy block $(\mathrm{mm})$; $P D R$ is paddy field drainage $(\mathrm{mm})$ that is excess water discharged from paddy fields and collected in the drainage ditch (Figure 1); and $t$ is the time step (day). In a modeling approach, DMWR can be simulated as a fraction of $A W S[5,6,8,15]$ :

$$
D M W R_{t}=A W S_{t} \times D M C_{y}
$$

where $D M C$ is the delivery management coefficient (fraction); and $y$ represents a year.

It has been reported that $D M C$ varies depending on farming practices and weather conditions $[5,8,15]$. When an $A W S$ or irrigation operation is recorded, DMC can be estimated by calculating the irrigation water requirement [5]. For modeling in ungauged watersheds, $D M C$ can be assumed from the literature [8].

$P D R_{t}$ can be estimated from the paddy water balance:

$$
P D_{t}=P D_{t-1}+R A I N_{t}+I R_{t}-\left(P D R_{t}+E T_{t}+I N F_{t}\right)
$$

where $P D$ is the ponding depth $(\mathrm{mm}) ; R A I N$ is the rainfall depth $(\mathrm{mm}) ; E T$ is the actual evapotranspiration $(\mathrm{mm})$; and $I N F$ is the infiltration $(\mathrm{mm}) . E T_{t}$ can be estimated by multiplying the reference evapotranspiration by a crop coefficient (Table 1). This study estimated the reference evapotranspiration using the Food and Agriculture Organization (FAO) Penman-Monteith equation [30] and the crop coefficient proposed for a Korean rice paddy [8]. INF is dependent of the soil texture of the paddy field, and thus it was assumed to be constant in this study [31]. PDR was determined by 
the level of the ponded water relative to the height of the paddy field outlet $(L H)(\mathrm{mm}$, Table 1). PDR occurs only when $P D$ is greater than $L H[8,29]$ :

$$
\begin{gathered}
P D R_{t}=f\left(H_{t}\right)=f\left(P D_{t}-L H_{t}\right) \text { when } P D_{t}>L H_{t} \\
P D R_{t}=0 \text { when } P D_{t} \leq L H_{t}
\end{gathered}
$$

where $H$ is the depth of flow above the upstream crest of the weir (the water head of the weir) (Figure 1c).

Table 1. Seasonal crop coefficients and outlet heights of paddy fields in Korea [8,32].

\begin{tabular}{ccccccccccccccccccc}
\hline \multirow{2}{*}{ Parameter } & \multirow{2}{*}{ P.S. } & \multirow{2}{*}{ T.S. } & \multicolumn{11}{c}{ Growing and Harvesting Season (10-days) } \\
\cline { 4 - 15 } & & & $\mathbf{1}$ & $\mathbf{2}$ & $\mathbf{3}$ & $\mathbf{4}$ & $\mathbf{5}$ & $\mathbf{6}$ & $\mathbf{7}$ & $\mathbf{8}$ & $\mathbf{9}$ & $\mathbf{1 0}$ & $\mathbf{1 1}$ & $\mathbf{1 2}$ & $\mathbf{1 3}$ & $\mathbf{1 4}$ & $\mathbf{1 5}$ \\
\hline$K_{c}$ & 0.78 & 0.78 & 0.78 & 0.97 & 1.07 & 1.16 & 1.28 & 1.45 & 1.5 & 1.58 & 1.46 & 1.45 & 1.25 & 1.01 & 1.01 & 1.01 & 1.01 \\
$L H(\mathrm{~mm})$ & 66.1 & 80.9 & 74 & 57.3 & 34.6 & 72.9 & 67.2 & 57.7 & 63.4 & 67.2 & 66.1 & 66.1 & 66.1 & 66.1 & 66.1 & 66.1 & 66.1 \\
\hline
\end{tabular}

$K_{c}$ is crop coefficient, $L H$ is the height of the paddy field outlet, P.S. is a preparation season for transplanting, T.S. is a season for transplanting.

There are two widely employed parameterization schemes representing the routing function $f\left(H_{t}\right)$; conceptual and physically-based parameterization approaches.

\subsubsection{Conceptual Parameter Approach}

A linear reservoir theory linearly relates outflow rate to storage volume using a storage constant, which is one of the conceptual models widely used in hydrology $[33,34]$. In this study, the conceptual parameter approach $(\mathrm{CON})$ assumes a linear relationship between paddy field drainage and the head $\left(H_{t}\right)$ of water above the outlet weir crest $[18,19,29]$ :

$$
f\left(H_{t}\right)=a H_{t}
$$

where $a$ is a conceptual parameter representing the drainage capacity of a paddy outlet (dimensionless) (Table 2). The values of $a$ range between zero and one. An upper limit of one means that the amount of water stored above the outlet weir crest is completely drained in a day [29]. Conversely, the lower limit of zero is when no water is drained out of the paddy field; this is not a realistic case as the ponded water always leaks through the levee. As such, the lower limit should always be greater than zero. In the Tank model developed for Korean irrigation watersheds, which also adopts the linear reservoir scheme, the lower limit of the coefficient, $a$ for the side outlet of the top layer, is typically set to 0.08 to represent water leakage [4,35]. Following this assumption, the minimum value of $a$ in CON was fixed to 0.08 so that $a$ would vary from 0.08 to 1.00 .

Table 2. Overview of the conceptual and physically-based parameterization approaches compared in this study.

\begin{tabular}{ccc}
\hline Schemes & CON & PHY \\
\hline Description & Conceptual based parameter approach & Physically-based parameter approach \\
Routing scheme & Linear reservoir with threshold scheme & Broad-crested weir equation \\
Calibration parameter & $a$ & $A, K, W$ \\
Simulation time step & Daily & Hourly \\
\hline
\end{tabular}

$a$ is a conceptual parameter representing the drainage capacity of a paddy outlet, $\mathrm{A}$ is the area of a paddy field, $K$ is a parameter representing the overall flow condition, and $\mathrm{W}$ is the weir width perpendicular to the direction of flow. 


\subsubsection{Physically-Based Approach}

The drainage discharge rate of water at the outlet of a paddy plot can be hydraulically calculated using the broad-crested weir equation $[24,25,29,36]$ :

$$
Q\left(H_{t}\right)=\mu_{t} W\left(\frac{H_{t}}{1000}\right)^{1.5}
$$

where $Q(H)$ is drainage discharge $\left(\mathrm{m}^{3} / \mathrm{s}\right) ; \mu$ is a coefficient that represents the combined effects of the discharge and approach velocity coefficients; and $W$ is the weir width perpendicular to the direction of flow $(\mathrm{m})$. The combined coefficient, $\mu$ is determined using

$$
\mu_{t}=\frac{\sqrt{2 g}}{2}\left[\left(\frac{K^{2}-1}{K^{2}}\right)\left(\frac{L H_{t}+H_{t}}{K\left(L H_{t}+H_{t}\right)-H_{t}}\right)\right]^{0.5}
$$

where $K$ is a parameter representing the overall flow condition, varying from 1.7 for open channel flow to 2.0 for submerged flow. Both flow conditions are possible in a paddy field. As such, the parameter was assumed to vary between 1.7 and 2.0 in this study [24]. PHY updates the water balance calculations with rainfall depth on an hourly basis, and daily paddy field drainage is calculated using Equation (12):

$$
f\left(H_{t}\right)=1000\left(\sum_{h=1}^{24} Q\left(H_{h}\right) \frac{3600}{A}\right)
$$

where $A$ is the area of a paddy field $\left(\mathrm{m}^{2}\right)$. In this study, the value of $A$ was estimated to range between $1800 \mathrm{~m}^{2}$ and $5900 \mathrm{~m}^{2}$, based on 100 paddy plots in the central Korea. PHY assumes that paddy plots in an irrigation block are homogeneous (i.e., the paddy plots have the same parameter values $(A, K$, and $W)$ and water management practices).

\subsection{Estimation of Irrigation Return Flow from Paddy Drainage}

$R F$ does not include runoff discharge by rainfall but only the drainage of excess water supplied by irrigation $[3,16]$. To quantify RF from paddy fields, $P D R$ should be divided into surface runoff discharges $(P R O)$ and quick return flow $(P R F)$. Modeling is considered the most feasible way to separate them. In this study, we quantified $P R O$ and $P R F$ based on the following assumptions [3,16,17]:

1. Water is not irrigated (zero IR) within a rainfall event (RAIN).

2. Surface runoff discharge $(P R O)$ is always followed by irrigation water discharge $(P R F)$.

3. Irrigation water ponded in a paddy plot is consumed by ET and INF first, and then water ponded by RAIN is used.

INF is eventually discharged downstream in the form of groundwater flow, and thus the DRF amount is assumed to equal INF [12-14].

\subsection{Parameter Value Range Selection Using Expert Knowledge}

The parameters of PHY are physically defined; thus, their values can be measured in a field or explicitly adopted from literature, which is desirable when no measurements are available for model calibration (Table 3). In this study, we measured $A$ from 100 paddy fields using remotely sensed images and adopted the value ranges of $K$ and $W$ determined for paddy fields located in central Korea from the literature $[8,35]$. On the other hand, the parameter $a$ of the CON approach is highly conceptual and lumped, and as such, its determination may be challenging. The value range of $a$ can be adopted from the Tank model, but its range is still wide (i.e., 0.08 to 1.00 ). 
Table 3. Parameter value ranges of the conceptual (CON) and physically-based (PHY) approaches.

\begin{tabular}{ccccc}
\hline Scheme & Parameter & Definition & Min. & Max. \\
Wide-CON & $a$ & $\begin{array}{c}\text { Drainage capacity of a paddy outlet } \\
\text { (dimensionless) }\end{array}$ & 0.08 & 1 \\
Narrow-CON & $a$ & $\begin{array}{c}\text { Drainage capacity of a paddy outlet } \\
\text { (dimensionless) }\end{array}$ & 0.32 & 0.91 \\
PHY & $W$ & Weir width perpendicular to the \\
direction of flow (m) & 0.08 & 0.8 \\
PHY & $K$ & $\begin{array}{c}\text { Parameter representing the overall } \\
\text { flow condition (dimensionless) }\end{array}$ & 1.7 & 2.0 \\
PHY & $A$ & Area of a unit paddy field $\left(\mathrm{m}^{2}\right)$ & 1800 & 5900 \\
\hline
\end{tabular}

Constraints created from expert knowledge may reduce the range of potential $a$ values. The parameter $a$ conceptually represents the drainage capacity of paddy field outlets, which is a role similar to that of the physical parameter $W$ of PHY. For reduced modeling uncertainty, we attempted to narrow the range of $a$ through inversely determining its values by relating Equations (7), (10), and (12) to each other:

$$
a=\frac{P D R}{H_{0}}=\frac{1000\left[\sum_{h=1}^{24} \mu_{h} W\left(\frac{H_{h}}{1000}\right)^{1.5} \frac{3600}{A}\right]}{P D_{0}+R A I N_{0}-L H_{0}}
$$

where $P D_{0}, R A I N_{0}$, and $L H_{0}$ are the initial condition of ponding depth, rainfall, and outlet height, respectively. The $P D_{0}$ value of $35 \mathrm{~mm}$ was estimated from the average of ponding depths recommended for paddy fields [8], and the $L H_{0}$ value of $65 \mathrm{~mm}$ was determined from the average of paddy outlet heights found in the literature for central Korea [37]. RAIN 0 was set to $40 \mathrm{~mm}$, which is the average depth of daily rainfall greater than $10 \mathrm{~mm}$ during the growing season at the Suwon Meteorological Station: the weather station closest to the study areas. A $K$ value of 1.85 was selected from the average of the free (2.0) and submerged (1.7) flow conditions, and the $A$ value of $3300 \mathrm{~m}^{2}$ was calculated from the average of 100 paddy plots. Following this, we found a nonlinear relationship between $W$ and $a$ (Figure 2).

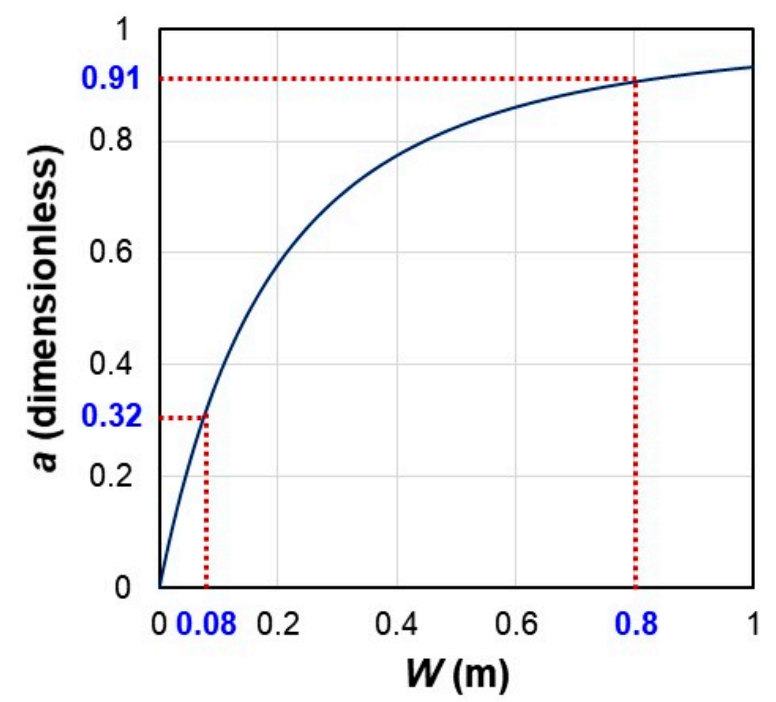

Figure 2. Relationship between the weir width $(W)$ and conceptual parameter representing the drainage capacity $(a)$. 
When $W$ varies from $0.08 \mathrm{~m}$ to $0.80 \mathrm{~m}$, based on the widths of weirs found in central Korea (Kang, 2015), $a$ varies from 0.32 to 0.91 . In the case of $\mathrm{CON}$, the theoretical ( 0.08 to 1.00$)$ and constrained (0.32 to 0.91 ) value ranges of $a$ are denoted as Wide-CON and Narrow-CON, respectively (Table 3).

It is worth noting that the constraining parameter space involves subjective and location-dependent selection processes, which may introduce uncertainty and errors into return flow estimates. For instance, the values of the terms in Equation (13), including $P D_{0}, L H_{0}$, and $R A I N_{0}$, were derived from literature and records made at a weather station close to the study area. In addition, $A$ was estimated from paddy fields sampled in the study area. Thus, the values need to be carefully adjusted to reflect the local field and weather conditions and thus to improve the accuracy of return flow modeling.

\subsection{Evaluating Uncertainty and Accuracy}

To assess the uncertainty of estimating the RF of an ungauged watershed, we quantified and compared the size of variations in RF estimates made using the CON and PHY approaches. The values of the conceptual and physically-based parameters were randomly sampled using a Monte-Carlo routine. A total of 200,000 parameter value sets were sampled from the uniform distribution bounded in the predefined ranges (Table 3). The RF uncertainty was quantified as the size of a $95 \%$ confidence envelope (95CI) of RF simulated using the sampled parameter sets:

$$
95 C I=\frac{1}{m} \times \sum_{j=1}^{m} Q_{97.5}(j)-Q_{2.5}(j)
$$

where $m$ is the total number of days in the test period, $Q_{97.5}(j)$ and $Q_{2.5}(j)$ are $97.5 \%$ and $2.5 \%$ percentiles on a $j$ day. A narrow $C I$ envelope indicates small uncertainty.

We compared TDR estimates to observed TDR to evaluate the performance of the (uncalibrated) CON and PHY approaches. The accuracy of TDR estimates made using parameter sets sampled in the Monte-Carlo simulation were evaluated using four performance statistics; the coefficient of determination $\left(R^{2}\right)$, Nash-Sutcliffe Efficiency (NSE) [38], a log-transformed NSE (NSE $\left.E_{l n}\right)$ [35,39], and percentage bias (PBIAS) [40]. Note that the accuracy of RF estimates could not be evaluated due to the absence of RF observation/reference data for comparison. RF can only be estimated but not measured from the water balance relationship. As such, RF cannot be quantified without modeling.

\section{Study Area and Data}

This study was conducted in a 10.3 ha paddy block located in Korea $\left(37^{\circ} 05^{\prime} \mathrm{N}, 127^{\circ} 06^{\prime} \mathrm{E}\right)$. The sizes of paddy fields in this block range from $1800 \mathrm{~m}^{2}$ to $5900 \mathrm{~m}^{2}$, with irrigation and drainage ditches located along both its sides (Figure 3). The paddy block is irrigated with surface water released from the Idong agricultural reservoir, and RF from the block is drained back to the Jinwi river. We monitored water balance in paddy blocks during the rice growing seasons in 2011 and 2012. Meteorological data including temperature, wind speed, relative humidity, and solar radiation were obtained from the Suwon National Weather station, $20 \mathrm{~km}$ away from the study area. Rainfall was observed at $10 \mathrm{~min}$ intervals using a rain gauge (tipping bucket type, HOBO Data Logging Rain Gauge, Bourne, US) placed $2 \mathrm{~km}$ away from the study area. Water level was measured every $10 \mathrm{~min}$ using ultrasonic sensors installed at the head and tail of the ditches. These measurements were converted to discharge using a stage-discharge relationship developed for ditches based on regression analysis [29] (Figure 3). The observations of DMC and INF were provided to the model as the boundary condition to explicitly compare $\mathrm{CON}$ and $\mathrm{PHY}$ approaches. The seasonal variations in $L H$ and crop coefficients were found in the literature and adopted for this study $[2,8,32,37]$. Measured drainage was compared to model predictions to evaluate the performance of uncalibrated parameter approaches. 

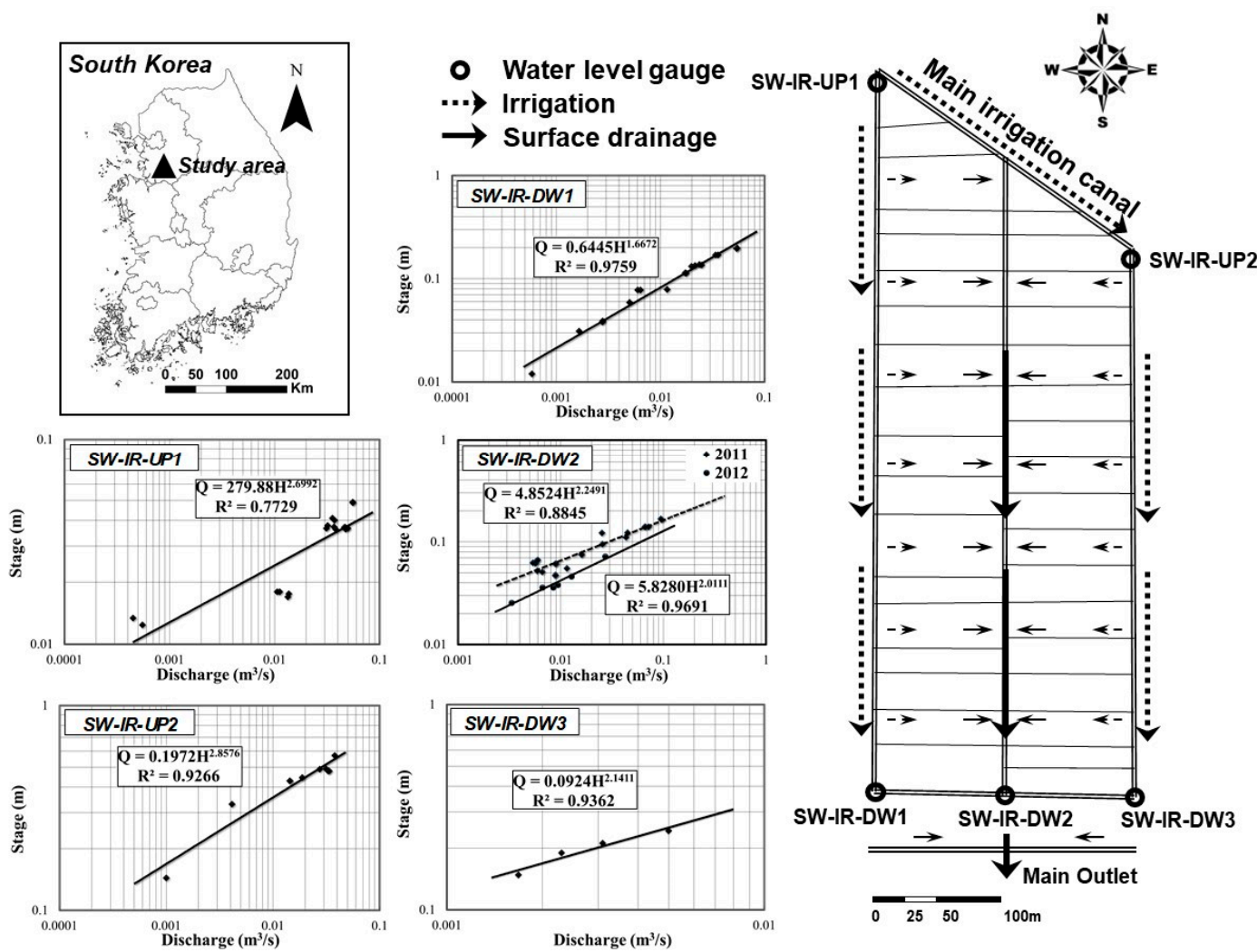

Figure 3. Schematics of the irrigation and drainage monitoring system for the study paddy block.

\section{Results and Discussions}

\subsection{Uncertainty and Accuracy of Conceptual and Physically-Based Parameterization Approaches}

The Wide-CON approach provided large uncertainty (or a wide range of variations) when predicting daily $R F$ and TDR (Figure 4). The uncertainty in $R F(9.31 \mathrm{~mm} /$ day) mostly originated from the $P R F\left(9.28 \mathrm{~mm} /\right.$ day). As a result, the $R_{R F}$ of Wide-CON varied from $27 \%$ to $83 \%$ (Figure 5). On the other hand, the bandwidth ( $3.85 \mathrm{~mm} /$ day) of $R F$ uncertainty provided by Narrow-CON, constrained with expert knowledge, was substantially narrower than that of Wide-CON, and $R_{R F}$ ranged from $77 \%$ to $82 \%$ (Figures 5 and 6). The PHY approach provided the narrowest RF uncertainty bandwidth of $3.22 \mathrm{~mm} /$ day (Figures 5 and 7). However, differences between the $R_{R F}$ ranges provided by Narrow-CON and PHY were negligible.

It is expected that models with higher complexity may suffer from greater predictive uncertainty, as stated by Beven [41]: “More complexity means more parameters, more parameters mean more calibration problems, more calibration problems will often mean more uncertainty in the predictions, particularly outside the range of the calibration data." However, we found that prior information of physically-based parameters (i.e., the value ranges of $W, K$, and $A$ in this study), could effectively suppress uncertainty even without any parameter calibration (Figures 5 and 7). In the case of CON, expert knowledge could reasonably link the conceptual parameter to the feature of a paddy plot and then effectively constrain its value range based on hydraulic reasoning (Figures 4-6). The Narrow-CON approach also improved the accuracy of daily TDR modeling compared to Wide-CON (Figures 4-6). This demonstrates the usefulness of employing expert knowledge in modeling practices. Such findings are consistent with the previous studies that have demonstrated that topography-driven information by expert knowledge can increase process realism and predictive power while reducing the need for calibration in ungauged watersheds [26-28,42]. 


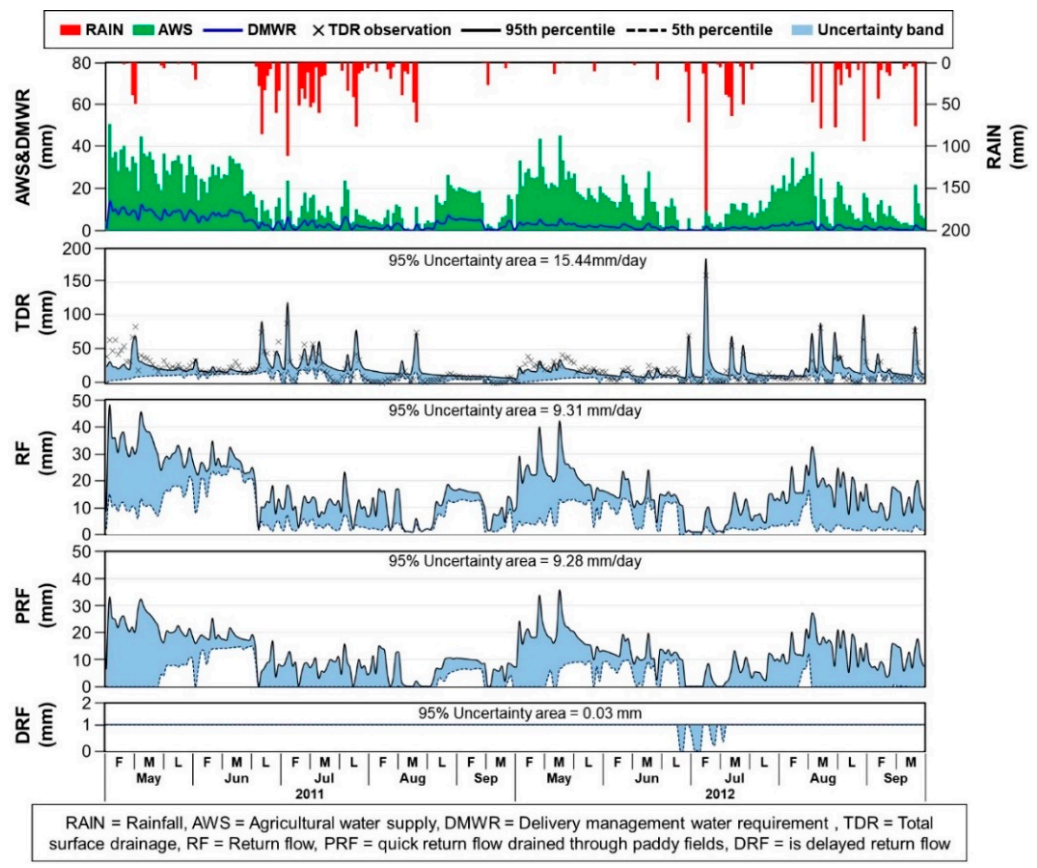

Figure 4. Temporal variations of inputs (RAIN and $A W S$ ), outputs ( $D M W R, T D R, R F, P R F$, and $D R F)$, and uncertainty (the $95 \%$ confidence interval) of output modeling using the Wide-CON approach. Simulated TDR is compared with the observations.
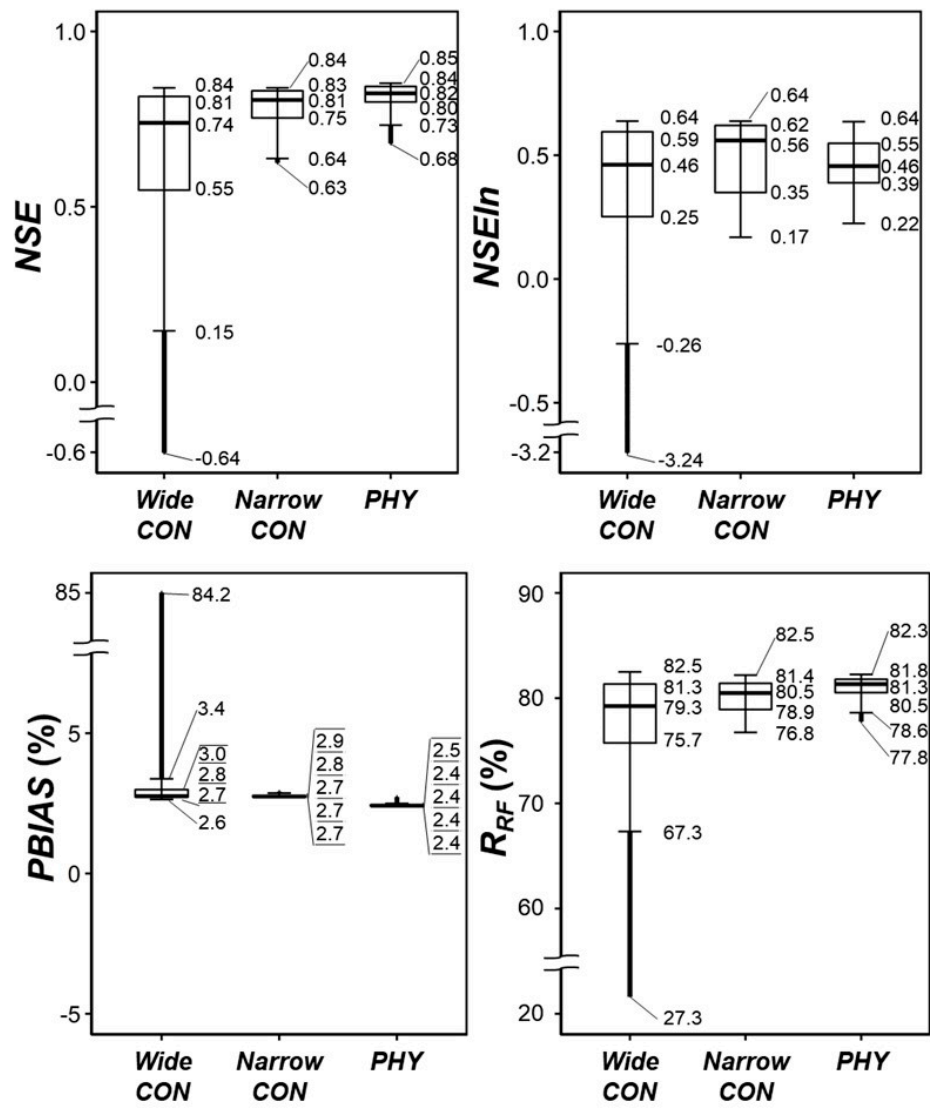

Figure 5. Accuracy statistics of predicting $T D R$ and uncertainty ranges of $R_{R F}$ calculated using the conceptual and physically-based parameter approaches. The height of a box plot is the interquartile range (IQR) (or the distance between the 25 th and 75 th percentiles). The ends of whiskers represent the minimum and maximum values. Circles outside the whisker ends are outliers. 


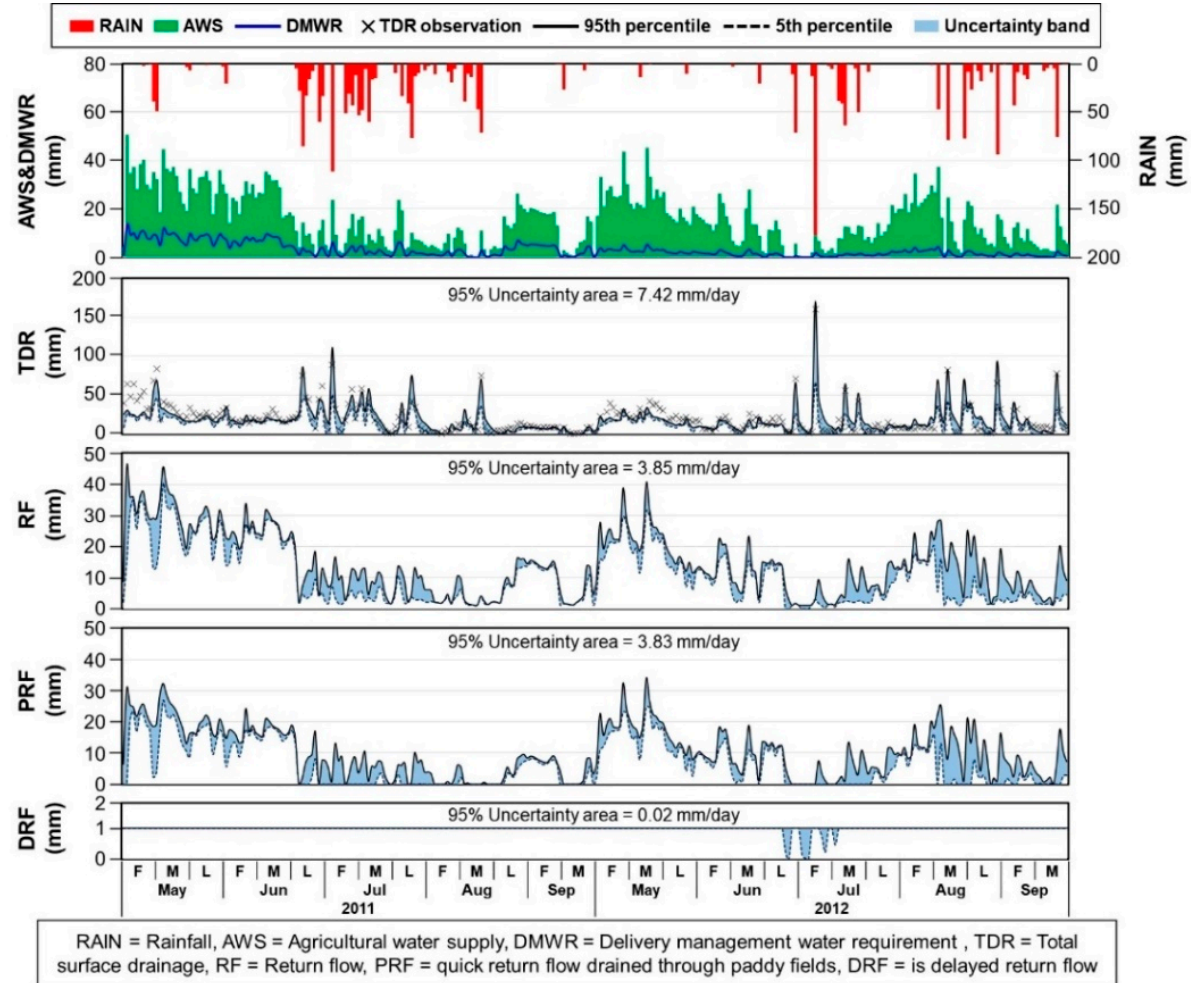

Figure 6. Temporal variations of inputs (RAIN and $A W S$ ), outputs ( $D M W R, T D R, R F, P R F$, and $D R F)$, and uncertainty (the $95 \%$ confidence interval) of output modeling using the Narrow-CON approach. Simulated TDR is compared with the observations.

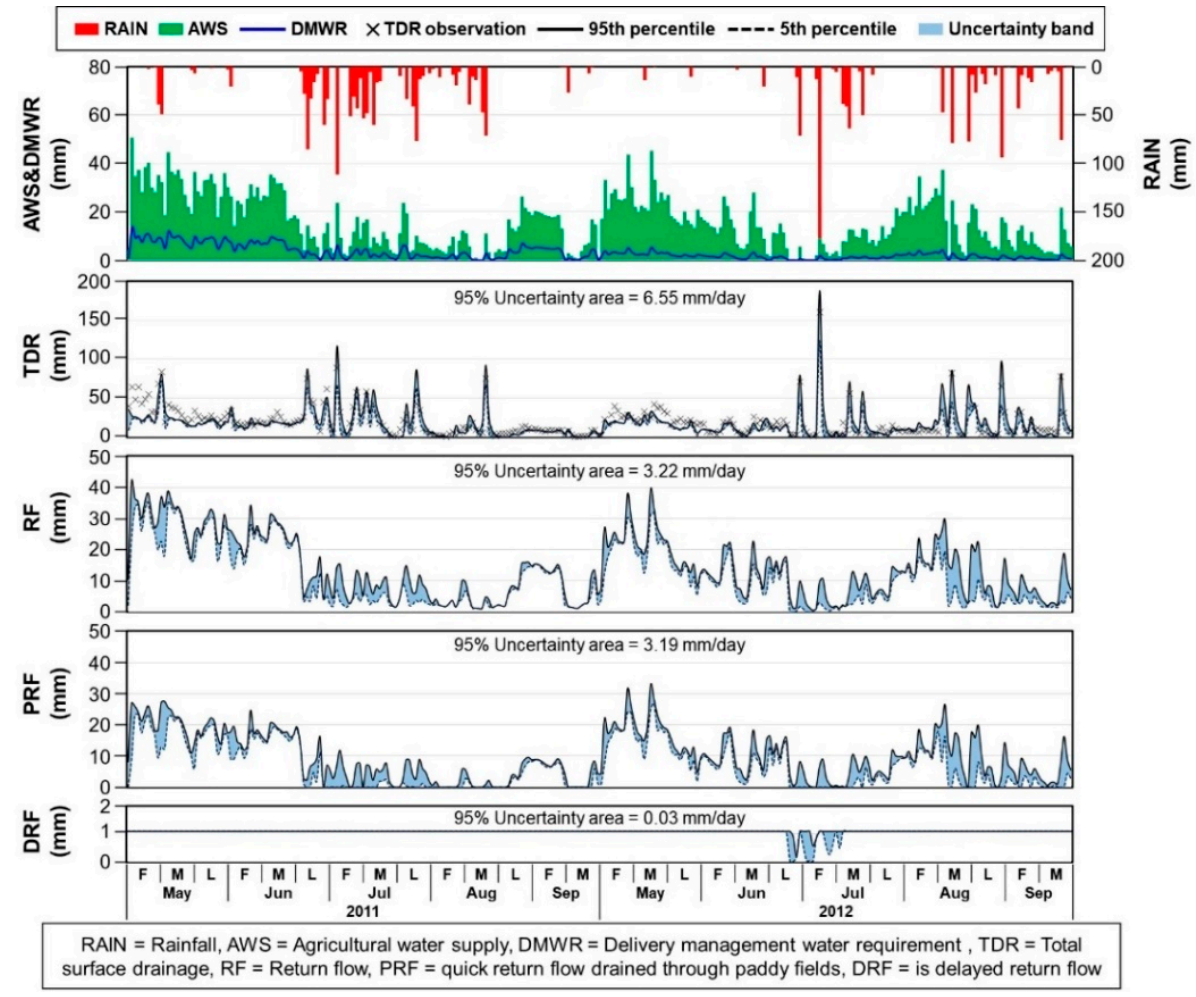

Figure 7. Temporal variations of inputs ( $R A I N$ and $A W S$ ), outputs ( $D M W R, T D R, R F, P R F$, and $D R F)$, and uncertainty (the $95 \%$ confidence interval) of output modeling using the PHY approach. Simulated $T D R$ is compared with the observations. 
The PHY approach yielded higher NSE and lower NSEln values than Narrow-CON $(p<0.001)$. However, the top $75 \%$ of both Narrow-CON and PHY yielded "good" overall performance statistics $(0.70<N S E$, and $|P B I A S|< \pm 10)$ [43]. Song et al. [29] found that the recession curves (or the gradients $\left(\frac{d Q}{d t}\right)$ after the peaks) of drainage discharge hydrographs simulated using CON and PHY could be similar to each other when they were calibrated to acceptable levels. This supports the similar performance of Narrow-CON and PHY in this study. CON can be simulated at both daily and hourly time steps, and it can be easily combined with existing daily or hourly hydrological models. On the other hand, PHY works only on hourly or shorter time steps and can be linked to models that simulate hydrological processes with an hourly time step [29].

\subsection{Potential of Conceptual and Physically-Based Parameterization Approaches}

The Narrow-CON and PHY approaches reproduced the drainage and RF components with acceptable performance and low uncertainty statistics. However, both provided many candidate parameter sets in the Monte-Carlo simulation [27,28]. The identification of the most representative parameter set from multiple candidates still remains challenging in water resources planning, especially for ungauged watersheds [44,45]. In such a case, outputs simulated using the candidate parameter sets are selected as the ensemble members, and their median is often selected to represent the outputs [26]. To investigate the potential of the CON and PHY approaches as a way to predict $R_{R F}$ (total RF ratio) for ungauged watersheds, this study compared the medians (Narrow-CON-Median and PHY-Median) of ensemble $R F$ identified from simulating the water balance using the CON and PHY approaches to $R F$ predicted using the CON and PHY modeling calibrated to the observed TDR (CON-BestNSE and PHY-BestNSE). For comparison, we added another uncalibrated CON approach that sets $a$ to 1 (CON-a1), assuming that the head of water above the outlet weir crest is completely drained in a day and thus does not require calibration.

As expected, $\mathrm{CON}-\mathrm{a} 1$ produced inferior performance statistics than the others in predicting TDR. Especially, CON-a1 did not predict the low values of TDR accurately (negative $N S E_{l n}$ values in Table 4). Such a poor performance of $\mathrm{CON}-\mathrm{a} 1$ should be attributed to the fact that the approach does not account for the delay of runoff or $R F$ caused by the storage of a paddy field (Table 4) [29]. This demonstrates that the assumption may not be applicable to irrigation blocks or seasons that have significant water storage capacity. Narrow-CON-Median and PHY-Median could predict the total RF ratio as accurately as calibrated ones (CON-BestNSE and PHY-BestNSE). This suggests that the ensemble CON and PHY approaches may be a useful alternative to parameter calibration when measurements are not available for calibration (Table 4).

Table 4. Performance measures of the uncalibrated, ensemble, and calibrated CON and PHY approaches.

\begin{tabular}{|c|c|c|c|c|c|c|}
\hline \multicolumn{2}{|c|}{ Performance Measures } & $\begin{array}{l}\text { CON } \\
a=1\end{array}$ & $\begin{array}{c}\text { CON } \\
\text { Best } \\
\text { NSE }^{a}\end{array}$ & $\begin{array}{c}\text { Narrow-CON } \\
\text { Median }^{b}\end{array}$ & $\begin{array}{c}\text { PHY } \\
\text { Best } \\
\text { NSE }^{\text {a }}\end{array}$ & $\begin{array}{c}\text { PHY } \\
\text { Median }^{b}\end{array}$ \\
\hline \multicolumn{2}{|c|}{$R^{2}$} & 0.79 & 0.84 & 0.83 & 0.86 & 0.86 \\
\hline \multicolumn{2}{|c|}{$N S E$} & 0.69 & 0.84 & 0.83 & 0.85 & 0.83 \\
\hline \multicolumn{2}{|c|}{$N S E_{l n}$} & -0.05 & 0.44 & 0.56 & 0.56 & 0.46 \\
\hline \multicolumn{2}{|c|}{ PBIAS (\%) } & 3 & 3 & 6 & 2 & 5 \\
\hline \multirow{3}{*}{$R_{R F}(\%)$} & 2011 & 86 & 85 & 83 & 84 & 84 \\
\hline & 2012 & 79 & 77 & 75 & 76 & 77 \\
\hline & Entire period & 82 & 81 & 80 & 80 & 81 \\
\hline
\end{tabular}

${ }^{a}$ The performance of the parameter set for the highest NSE in the all sampled sets; ${ }^{\mathrm{b}}$ The performance of the median of daily uncertainty intervals.

\section{Conclusions}

This study evaluated the uncertainty and performance of the two parameterization approaches, PHY and CON, in estimating the RF of an ungauged, heavily irrigated watershed. The physically-based 
approach allowed us to directly measure parameter values at a field or adopt them from literature. The conceptual approach could take advantage of hydrological reasoning to confine the parameter space and thus reduce modeling uncertainty. Based on the results presented in this study we could draw the following conclusions.

1. The results showed that the physically-based parameterization could effectively regulate the behavior of the RF model and thus produce smaller uncertainty compared to that of the conceptual approach, suggesting and confirming the potential of a physically-based approach as a way to effectively reduce modeling uncertainty without parameter calibration.

2. When the value ranges of a conceptual parameter were naively (or simply) defined, the CON produced wide uncertainty in RF estimates.

3. The conceptual parameter could be reasonably related to the physical and hydraulic characteristics of a study field, substantially reducing the size of uncertainty in RF estimates to as small as that of PHY.

4. Narrow-CON and PHY reproduced TDR at similar and acceptable accuracy, and the performance of the ensemble RF (Narrow-CON-Median and PHY-Median) was comparable to that of the calibrated approaches (CON-BestNSE and PHY-BestNSE).

Such findings highlighted the potential of a conceptual parameterization approach combined with expert knowledge as an efficient way to predict the water balance of an irrigation block. These results exemplify the benefit of physically-based reasoning for modeling ungauged areas.

Author Contributions: Conceptualization, J.-H.S., Y.H., S.H. and M.-S.K.; methodology, J.-H.S., Y.H., S.H. and M.-S.K.; software, J.-H.S.; validation, J.-H.S., S.H. and Y.H.; investigation, J.-H.S., S.H. and Y.H.; resources, J.-H.S., M.-S.K. and Y.H.; data curation, J.-H.S. and S.H.; writing—original draft preparation, J.-H.S.; writing-review and editing, Y.H. and M.-S.K.; visualization, J.-H.S., S.H., Y.H. and M.-S.K.; supervision, M.-S.K. and Y.H.; funding acquisition, M.-S.K. and J.-H.S. All authors have read and agreed to the published version of the manuscript.

Funding: This research was supported by the Basic Science Research Program through the National Research Foundation of Korea (NRF) funded by the Ministry of Education (NRF-2017R1D1A1B03034463). This research was also supported by funds provided to the Rural Research Institute of Korea Rural Community Corporation by the Ministry of Agriculture, Food and Rural Affairs as part of the project: "Development of improved farming methods for agricultural non-point source pollution reduction".

Conflicts of Interest: The authors declare no conflict of interest.

\section{References}

1. Dewandel, B.; Gandolfi, J.-M.; de Condappa, D.; Ahmed, S. An efficient methodology for estimating irrigation return flow coefficients of irrigated crops at watershed and seasonal scale. Hydrol. Process. 2008, 22, 1700-1712. [CrossRef]

2. Kang, M.; Park, S. Modeling water flows in a serial irrigation reservoir system considering irrigation return flows and reservoir operations. Agric. Water Manag. 2014, 143, 131-141. [CrossRef]

3. Kim, H.K.; Jang, T.I.; Im, S.J.; Park, S.W. Estimation of irrigation return flow from paddy fields considering the soil moisture. Agric. Water Manag. 2009, 96, 875-882. [CrossRef]

4. Song, J.-H.; Her, Y.; Park, J.; Lee, K.-D.; Kang, M.-S. Simulink implementation of a hydrologic model: A Tank model case study. Water 2017, 9, 639. [CrossRef]

5. Song, J.-H.; Kang, M.S.; Song, I.; Jun, S.M. Water balance in irrigation reservoirs considering flood control and irrigation efficiency variation. J. Irrig. Drain. Eng. 2016, 142, 04016003. [CrossRef]

6. Song, J.H.; Song, I.; Kim, J.-T.; Kang, M.S. Characteristics of irrigation return flow in a reservoir irrigated district. J. Korean Soc. Agric. Eng. 2015, 57, 69-78.

7. Chien, C.-P.; Fang, W.-T. Modeling irrigation return flow for the return flow reuse system in paddy fields. Paddy Water Environ. 2012, 10, 187-196. [CrossRef]

8. Song, J.-H.; Her, Y.; Jun, S.M.; Hwang, S.; Park, J.; Kang, M.-S. Lessons from assessing uncertainty in agricultural water supply estimation for sustainable rice production. Agronomy 2019, 9, 662. [CrossRef]

9. Zulu, G.; Toyota, M.; Misawa, S. Characteristics of water reuse and its effects on paddy irrigation system water balance and the riceland ecosystem. Agric. Water Manag. 1996, 31, 269-283. [CrossRef] 
10. Grafton, R.Q.; Williams, J.; Perry, C.J.; Molle, F.; Ringler, C.; Steduto, P.; Udall, B.; Wheeler, S.A.; Wang, Y.; Garrick, D.; et al. The paradox of irrigation efficiency. Science 2018, 361, 748-750. [CrossRef]

11. Tan, X.; Shao, D.; Gu, W. Improving water reuse in paddy field districts with cascaded on-farm ponds using hydrologic model simulations. Water Resour. Manag. 2018, 32, 1849-1865. [CrossRef]

12. Choo, T.-H. A study on return flow ratio of irrigation for a paddy field in pumping station by water balance method. J. Korea Water Resour. Assoc. 2004, 37, 249-255. [CrossRef]

13. Chung, S.-O.; Park, K.-J. Irrigation return flow measurements and analysis in a small size paddy area. J. Korea Water Resour. Assoc. 2004, 37, 517-526. [CrossRef]

14. Kim, T.-C.; Lee, H.-C.; Moon, J.-P. Estimation of return flow rate of irrigation water in Daepyeong pumping district. J. Korean Soc. Agric. Eng. 2010, 52, 41-49.

15. Kim, J.-S.; Oh, S.-Y.; Oh, K.-Y.; Cho, J.-W. Delivery management water requirement for irrigation ditches associated with large-sized paddy plots in Korea. Paddy Water Environ. 2005, 3, 57-62. [CrossRef]

16. Im, S. Modeling Irrigation Return Flow from Paddy Fields on Agricultural Watersheds; Seoul National University: Seoul, Korea, 2000.

17. Song, J.-H. Hydrologic Analysis System with Multi-Objective Optimization for Agricultural Watersheds; Seoul National University: Seoul, Korea, 2017.

18. Chang, Y.-C.; Kan, C.-E.; Lin, G.-F.; Chiu, C.-L.; Lee, Y.-C. Potential benefits of increased application of water to paddy fields in Taiwan. Hydrol. Process. 2001, 15, 1515-1524. [CrossRef]

19. Chen, R.-S.; Yang, K.-H. Terraced paddy field rainfall-runoff mechanism and simulation using a revised tank model. Paddy Water Environ. 2011, 9, 237-247. [CrossRef]

20. Chen, S.-K.; Chen, R.-S.; Yang, T.-Y. Application of a tank model to assess the flood-control function of a terraced paddy field. Hydrol. Sci. J. 2014, 59, 1020-1031. [CrossRef]

21. Yoshinaga, I.; Miura, A.; Hitomi, T.; Hamada, K.; Shiratani, E. Runoff nitrogen from a large sized paddy field during a crop period. Agric. Water Manag. 2007, 87, 217-222. [CrossRef]

22. Jang, T.I.; Kim, H.K.; Im, S.J.; Park, S.W. Simulations of storm hydrographs in a mixed-landuse watershed using a modified TR-20 model. Agric. Water Manag. 2010, 97, 201-207. [CrossRef]

23. Kang, M.S.; Koo, J.H.; Chun, J.A.; Her, Y.G.; Park, S.W.; Yoo, K. Design of drainage culverts considering critical storm duration. Biosyst. Eng. 2009, 104, 425-434. [CrossRef]

24. Odhiambo, L.O.; Murty, V.V.N. Modeling water balance components in relation to field layout in lowland paddy fields. I. Model development. Agric. Water Manag. 1996, 30, 185-199. [CrossRef]

25. Wu, R.-S.; Sue, W.-R.; Chien, C.-B.; Chen, C.-H.; Chang, J.-S.; Lin, K.-M. A simulation model for investigating the effects of rice paddy fields on the runoff system. Math. Comput. Model. 2001, 33, 649-658. [CrossRef]

26. Gharari, S.; Shafiei, M.; Hrachowitz, M.; Kumar, R.; Fenicia, F.; Gupta, H.V.; Savenije, H.H.G. A constraint-based search algorithm for parameter identification of environmental models. Hydrol. Earth Syst. Sci. 2014, 18, 4861-4870. [CrossRef]

27. Gharari, S.; Hrachowitz, M.; Fenicia, F.; Gao, H.; Savenije, H.H.G. Using expert knowledge to increase realism in environmental system models can dramatically reduce the need for calibration. Hydrol. Earth Syst. Sci. 2015, 18, 4839-4859. [CrossRef]

28. Hrachowitz, M.; Fovet, O.; Ruiz, L.; Euser, T.; Gharari, S.; Nijzink, R.; Freer, J.; Savenije, H.H.G.; Gascuel-Odoux, C. Process consistency in models: The importance of system signatures, expert knowledge, and process complexity. Water Resour. Res. 2014, 50, 7445-7469. [CrossRef]

29. Song, J.-H.; Her, Y.; Hwang, S.; Park, J.; Yoon, K.-S.; Kang, M.S. Evaluating the applicability of drainage routing schemes for paddy fields. J. Irrig. Drain. Eng. 2020, in press.

30. Allen, R.G.; Pereira, L.S.; Raes, D.; Smith, M. Crop Evapotranspiration-Guidelines for Computing Crop Water Requirements; Food and Agriculture Organization of the United Nations: Rome, Italy, 1998.

31. Song, J.-H.; Kang, M.-S.; Song, I.; Hwang, S.-H.; Park, J.; Ahn, J.-H. Surface drainage simulation model for irrigation districts composed of paddy and protected cultivation. J. Korean Soc. Agric. Eng. 2013, 55, 63-73.

32. Yoo, S.-H.; Choi, J.-Y.; Lee, S.-H.; Oh, Y.-G.; Yun, D.K. Climate change impacts on water storage requirements of an agricultural reservoir considering changes in land use and rice growing season in Korea. Agric. Water Manag. 2013, 117, 43-54.

33. Nash, J.E. The form of the instantaneous unit hydrograph. IAHS Publ. 1957, 3, 114-121.

34. Purcell, P.J. Physical Analog of the Linear Reservoir. J. Hydrol. Eng. 2006, 11, 184-187. [CrossRef] 
35. Song, J.-H.; Her, Y.; Park, J.; Kang, M.-S. Exploring parsimonious daily rainfall-runoff model structure using the hyperbolic tangent function and Tank model. J. Hydrol. 2019, 574, 574-587. [CrossRef]

36. Chow, V.T.; Maidment, D.R.; Mays, L.W. Applied Hydrology; McGraw-Hill: New York, NY, USA, 1988.

37. Kang, M.S.; Park, S.W.; Lee, J.J.; Yoo, K.H. Applying SWAT for TMDL programs to a small watershed containing rice paddy fields. Agric. Water Manag. 2006, 79, 72-92. [CrossRef]

38. Nash, J.E.; Sutcliffe, J.V. River flow forecasting through conceptual models part I-A discussion of principles. J. Hydrol. 1970, 10, 282-290. [CrossRef]

39. Oudin, L.; Andréassian, V.; Mathevet, T.; Perrin, C.; Michel, C. Dynamic averaging of rainfall-runoff model simulations from complementary model parameterizations. Water Resour. Res. 2006, 42. [CrossRef]

40. Gupta, H.V.; Sorooshian, S.; Yapo, P.O. Toward improved calibration of hydrologic models: Multiple and noncommensurable measures of information. Water Resour. Res. 1998, 34, 751-763. [CrossRef]

41. Beven, K.J. Rainfall-Runoff Modelling: The Primer; John Wiley \& Sons: Chichester, UK, 2001; ISBN 1-119-95101-1.

42. Vinogradov, Y.B.; Semenova, O.M.; Vinogradova, T.A. An approach to the scaling problem in hydrological modelling: The deterministic modelling hydrological system. Hydrol. Process. 2011, 25, 1055-1073. [CrossRef]

43. Moriasi, D.N.; Gitau, M.W.; Daggupati, P. Hydrologic and water quality models: Performance measures and evaluation criteria. Trans. ASABE 2015, 58, 1763-1785.

44. Efstratiadis, A.; Koutsoyiannis, D. One decade of multi-objective calibration approaches in hydrological modelling: A review. Hydrol. Sci. J. 2010, 55, 58-78. [CrossRef]

45. Khu, S.T.; Madsen, H. Multiobjective calibration with Pareto preference ordering: An application to rainfall-runoff model calibration. Water Resour. Res. 2005, 41. [CrossRef]

(C) 2020 by the authors. Licensee MDPI, Basel, Switzerland. This article is an open access article distributed under the terms and conditions of the Creative Commons Attribution (CC BY) license (http://creativecommons.org/licenses/by/4.0/). 